Commentary on: Inflexibly Enacted Traditional Masculinity Norms (IE-TMNs) and Their Impact on Adolescent and Young Adult Depression: The Hybrid Case Study of "Tommy"

\title{
Reconstructing and/or Deconstructing Masculinity: A Commentary on the Case of "Tommy"
}

\section{ETHAN HOFFMAN ${ }^{\mathrm{a}, \mathrm{b}}$ \& MICHAEL E. ADDIS ${ }^{\mathrm{a}}$}

\author{
${ }^{a}$ Frances L. Hiatt School of Psychology, Clark University, Worcester, Massachusetts \\ ${ }^{\mathrm{b}}$ Correspondence regarding this article should be sent to Ethan Hoffman, Frances L. Hiatt School of Psychology, \\ Clark University, 950 Main Street, Worcester, MA 01610 \\ Email: ethoffman@clarku.edu
}

\begin{abstract}
Men's psychological well-being has in recent decades garnered increasing attention in research, clinical practice, and larger society. Dewey's insightful case study provides an occasion for reflecting on the multiple conceptual lenses that can be used to understand and work with masculinity in psychotherapy. In this commentary, we discuss how these conceptualizations of masculinity facilitate different approaches to psychotherapy at the levels of treatment planning and intervention. We offer our own approach to masculine identity work, noting specific points of contrast with the approach illustrated by Dewey. Finally, we critically explore the clinical and societal implications of concepts like "toxic masculinity" and "healthy masculinity" in light of social justice pursuits for gender equality. Throughout, we emphasize the importance for clinicians to make deliberate choices about how masculinity is conceptualized and to consider the pragmatic consequences of these conceptual choices.
\end{abstract}

Key words: masculinity; depression; positive masculinity; cognitive restructuring; cognitive defusion; feminist therapy; case study; hybrid case study

We appreciate the opportunity to comment on this hybrid case study. Many questions animate the psychology of men and masculinities (PMM). Dewey's work with "Tommy" is rich, nuanced, and breathes life into these questions: How can we best engage men in psychotherapy? How does masculinity relate to psychological distress? How should therapists conceptualize masculinity in the first place? In the following commentary, we offer our perspective on these and other questions pertinent to gender-sensitive psychotherapy from the vantage point of PMM scholarship.

PMM is a field that includes multiple theoretical perspectives - we certainly cannot speak for the whole of it. Our own functional contextualist approach to PMM gives heavy consideration to the practical impact of scholarship on society (Addis, Mansfield, \& Syzdek 2010). We think it is important to ascertain how well a theory "works": whether it helps us 
achieve goals in line with our scientific and socio-political values. We want to employ a concept of masculinity and an approach to gender-sensitive therapy with men that is both useful for clinicians and disrupts structures that perpetuate gender inequality and other forms of injustice.

With that said:

\section{WHAT IS MASCULINITY?}

Current scholarship suggests a number of ways of conceptualizing masculinity, some overlapping and some mutually exclusive (Addis \& Hoffman, 2019). Here are just a few examples:

A. Biological: Masculinity is the cognitive, emotional, and behavioral expression of male biological sex and secondary sex characteristics.

B. Cognitive: Masculinity is a cognitive schema consisting of specific beliefs or norms about what it means to be a man and how men should behave (i.e., "real men don't cry" or "a man should support his family").

C. Behavioral: Masculinity is any behavior that functions to mark someone as "being a man" (i.e., boasting about a sexual fling or calling another man "gay")

D. Critical: Masculinities (plural) are the ideological systems that justify and maintain the dominance of straight, white men over women, people of color, and gender minorities.

There are a number of meaningful differences here. For example, some definitions treat masculinity more like a noun (something men have) and others treat masculinity more like a verb (something men do). Some, like the biological definition, construct masculinity as relatively immutable; others, like the cognitive or behavioral definitions, open up space to see masculinity as changeable. They also offer different answers to the question "where is masculinity?" A biological conceptualization locates masculinity in the body, a cognitive conceptualization locates it in the mind, while the critical definition locates it in both individuals and social structures.

The dominant way of conceptualizing masculinity within PMM research is as a set of social norms (bullet point B in the above list). Masculinity is typically measured in this literature with self-report surveys, in which participants rate either their agreement with masculine norms applied to men in general (i.e., "Men should never show weakness around others") or, alternately, how much they personally adhere to masculine norms (i.e., "I try to never show weakness around others"). There are a large number of such measures used in the research literature, including the Meanings of Adolescent Masculinity Scale (MAMS; Oransky \& Fisher, 2009) which Dewey employed in his case study. These questionnaires measure partially overlapping sets of norms. The Conformity to Masculine Norms Inventory (CMNI; Mahalik et al., 2003) captures a typical set of these norms: competitiveness, emotional control, risk-taking, violence, dominance, playboy, self-reliance, primacy of work, power over women, disdain for homosexuals, and pursuit of status.

Regardless of how masculinity is conceived, we believe it is crucial that clinicians think intentionally about how they conceptualize "masculinity" before diving into gender-sensitive 
therapy. Thoughtful deliberation is important because one's definition of masculinity will invariably affect the way a case is formulated and will suggest distinct approaches to intervention. For instance, if masculinity is a set of beliefs, it follows that "working on a client's masculinity" will have to involve examining, restructuring, and/or defusing from those beliefs. If masculinity is a set of behaviors, then intervention will involve exploring the functions of existing "masculine" behaviors and learning new, more adaptive behaviors. If masculinity is an ideology that privileges straight, white men over other groups, it follows that intervention will focus on looking at what masculinity means in the context of a client's personal relationships (with friends, romantic partners, work colleagues, etc.) and how those meanings relate to larger social structures.

Dewey's hybrid case study integrates both cognitive and behavioral conceptualizations of masculinity. He describes masculinity as a set of social norms learned and internalized from a young age. Importantly, however, Dewey's case study does not focus on masculinity writ large but rather on the narrower construct of "inflexibly-enacted traditional masculinity norms" (IETMNs). With this term, Dewey refers to both (1) specific cognitive beliefs (i.e., "men should be fearless, in control, irresistible to women," etc.) and (2) a rigid way of behaving in response to those beliefs. The concept of IE-TMNs avoids pathologizing traditional masculine norms in and of themselves. As such, this concept undoubtedly engenders less pushback from male-identifying clients than a term like "toxic masculinity." Indeed, Dewey argues that masculine norms only become problematic when they become distorted or extreme (i.e., "I should never ask for help.") and when they inflexibly guide behavior despite producing undesired outcomes (i.e., engaging in casual flings even when doing so tends to produce feelings of shame or emptiness afterwards).

\section{CASE CONCEPTUALIZATION: HOW DOES MASCULINITY RELATE TO PSYCHOLOGICAL DISTRESS?}

There is now robust meta-analytic evidence that holding beliefs consistent with traditional masculinity (as measured by the CMNI) is associated with poorer mental health and greater reluctance to seek professional psychological help. Of all CMNI norms, self-reliance norms are the most consistently correlated with negative mental health outcomes across different studies (Wong et al., 2017). Emotional control, violence, power over women, dominance, and playboy norms also show relationships with negative mental health across studies, although the data are somewhat more mixed with regard to these norms compared to the data on self-reliance norms (Gerdes \& Levant, 2018). It is worth noting, however, that the effect sizes for the relationships between masculinity and mental health outcomes are small; for instance, masculine norm adherence only accounts for approximately $4.4 \%$ of the variance in psychological distress (Wong et al., 2017).

Although masculine norm adherence and negative mental health are clearly related, the causal mechanisms are murky. Men can experience distress both when they follow the dictates of masculine norms (i.e., engaging in dangerous risks) and when they fail to live up to those norms (i.e., feeling shame or being teased for expressing interest a gender non-typical interest; Levant, 2011; Pleck, 1995). Research shows that many men view masculinity as a status that is "hard won, but easily lost" and reliably respond to masculinity threats by engaging in behaviors that re- 
affirm their masculinity (Vandello \& Bosson, 2013). Because mental health conditions like depression are viewed as incongruent with traditional masculinity (Michniewicz et al., 2016), men may respond to negative moods by engaging in strategies that are consistent with traditional masculine norms. These strategies, such as suppression or substance use, provide short-term respite from negative mood. However, as Berke, Reidy, and Zeichner (2018) note, these types of strategies tend to be ineffective in the long-run and prevent men from developing more adaptive emotion regulation strategies. Finally, regardless of how masculinity might initially lead to distress, men who adhere more strongly to masculine norms are less likely to seek help from both formal and informal sources of support in response to psychological distress (Berger et al., 2013; Yousaf, Popat, \& Hunter, 2015). Taken together, traditional masculine norms appear to make men more vulnerable to psychopathology both directly, by encouraging dysfunctional behaviors and setting impossible-to-meet standards, and indirectly, through discouraging helpseeking and adaptive coping.

\section{MAKING A TREATMENT PLAN: TO RECONSTRUCT OR DECONSTRUCT?}

At several points in his case study, Dewey states that one of the treatment goals was for Tommy to construct a "healthy masculinity" (pp. 263, 281, \& 296). Elsewhere, Dewey uses a different term: "flexible masculinity" (pp. 289 \& 294). Although Dewey appears to use these terms interchangeably, we see them as pointing in meaningfully distinct directions. Aiming for a healthier "version" of masculinity suggests that it is the content of Tommy's initial beliefs about masculinity that are problematic. In contrast, "flexible" masculinity suggests instead that the issue here is how Tommy relates to those beliefs: that his beliefs about masculinity have begun to function as strict rules such that he follows the rules even when doing so produces negative consequences and he experiences shame when he breaks the rules.

Dewey's work with Tommy appears to more closely hew to the path of reconstructing a new version of masculinity. This clinical approach lends itself very well, as Dewey shows, to adapting principles and interventions from cognitive therapy, such as cognitive restructuring (Beck \& Emery, 2005). By the time that Tommy begins the work of reconstructing his beliefs about masculinity, he has already built a solid foundation for this skill in earlier sessions focused on restructuring depressogenic thoughts. When they turn to IE-TMNs, Dewey first helps Tommy to identify automatic thoughts — such as his belief that he will not be respected if he is not strong enough. Thanks to the prior foundational work, Tommy is able to quickly generate more adaptive and realistic alternatives without prompting (p. 277).

Over several sessions, Dewey employs a combination of cognitive restructuring and gentle but informative psychoeducation about masculinity and male gender socialization. Through the course of this work, Tommy becomes increasingly aware of the messages he has received about masculinity while beginning to doubt that those messages "are true" (p. 281). By the end of the portion of treatment focused on IE-TMNs, Tommy has decided that he wants both "to be someone who works hard, can show strength in times of conflict, and can provide for others" and to "be able to talk about his feelings more openly with his friends and ask for help when he [is] struggling" (p. 285). Taken as a whole, Tommy's movement from the rigid, all-or- 
nothing beliefs about masculinity expressed in the beginning of treatment to more balanced thoughts about masculinity is a testament to the effectiveness of Dewey's cognitive restructuring approach.

An alternative approach to intervention is to frame Tommy's difficulties as being less about the content of his beliefs about masculinity and more about the function of those beliefs. Whereas the approach described in the paragraph above aims to reconstruct masculinity, the goal of this second approach — which we follow in much of our clinical work with men - is to deconstruct masculinity. This second approach involves many of the same steps as those taken by Dewey. As in Dewey's approach, we believe it is essential for clients to identify and make explicit their underlying, automatic thoughts about masculinity. Where our approach differs is in what we do with those beliefs.

It is our experience that, for many men, being seen as a "real man" or perceiving oneself as "manly" is nearly always a means to an end but not an end in and of itself. Our clients have often bought into a narrative that becoming a "real man" will help them in some way: to attract and maintain romantic connections, earn the respect of others, or bring professional success. In the language of Acceptance and Commitment Therapy, masculinity functions as a "process goal" rather than an "outcome goal" (Hayes, Strosahl, and Wilson, 2012, pp. 168-169). These outcome goals - the end to which masculinity is a means - are invariably revealing about client values. Thus, an important foundation in our work with men is values clarification. Were we to work with a client like Tommy, for example, we would be keen to explore his values around relationships and to clarify what he has found meaningful in his relationships with his mother, friends, ex-girlfriend, and more recent lovers.

When a client like Tommy clarifies his values (such as "closeness" or "intimacy"), those values become our north star. Beliefs about masculinity and the behavioral enactment of those beliefs are then assessed in light of the client's values. We encourage clients to explore the workability of beliefs about masculinity, such as "real men never show fear." Importantly, the question we pose is not whether the belief "real men never show fear" accurately reflects some biological or statistical truth about what is normal for men. Instead, the question is more practical: does acting in accordance with the belief that "real men never show fear" move a client towards their values, such as intimacy or closeness? By building distance between a client's values and IE-TMNs, we hope to foster a type of self-awareness in which masculinity becomes less central — just one of many identities and not the whole of the person.

Ultimately, our approach to deconstructing masculinity is about facilitating defusion (Hayes, Strosahl, \& Wilson, 2012, pp. 243-269). Our perspective is that clients may find that they are able to live more meaningful lives when masculinity - traditional, toxic, healthy, flexible, or otherwise - no longer serves as a standard against which the client relentlessly compares themselves. The risk of promoting a "flexible" or "healthy" masculinity is that doing so will lead clients to stay focused on masculinity as a process goal rather than help them to move closer towards their values. For example, Tommy's reconstruction of masculinity, away from being a playboy towards being more "chivalrous" (p. 286), may lead him to engage in more prosocial behaviors towards women. However, insofar as Tommy still believes that it is important to be masculine, he may still be concerned with proving this chivalry to others and 
may still experience anxiety in situations in which he perceives himself as being insufficiently protective of women. Thus, any focus on chivalry as a goal in its own right may distract from Tommy's apparently more fundamental goal of building "a close relationship" with a woman (p. 286). In addition, if therapists are concerned about the larger goal of promoting gender equality, they might explore with Tommy the ways in which chivalry, although perhaps less explicit than other forms of sexism, can still function to treat women as weak, needy, and generally less competent than men.

\section{POSITIVE MASCULINITY: CONCEPTUAL AND SOCIO-POLITICAL CONSIDERATIONS}

We agree with Dewey's perspective, voiced at the end of his case study, that the term "toxic masculinity" is unhelpful both in clinical work and in public-facing communication about PMM research. As Dewey notes, the term cements the idea that there is something inherently negative about masculinity. However, we respectfully dissent from Dewey's endorsement of "healthy masculinity" as a useful term. Although this term is much more likely to be met receptively in the here-and-now of the session, it has its own political and conceptual drawbacks.

The notion of "healthy masculinity" fits under the umbrella of the positive manhood paradigm, a perspective that emphasizes the positive aspects of male gender socialization (Kiselica, Benton-Wright, \& Englar-Carlson, 2016). Proponents of the positive masculinity paradigm argue that contemporary PMM research has largely centered around a deficit model of masculinity. Such a deficit model fails to account for the ways that masculine norms can be positive for men. Kiselica, Benton-Wright, and Englar-Carlson (2016, pp. 126-128) propose the following positive masculinity characteristics: action-oriented relational styles; male ways of caring; generative fatherhood; self-reliance; the worker-provider tradition; respect for women; courage, daring, and risk-taking; group orientation; male forms of service; use of humor; and male heroism.

It is not clear, however, how distinct these characteristics of positive masculinity are from the norms measured by questionnaires like the CMNI - that is, how different positive masculinity is from the traditional masculinity associated with negative mental health. The difference does not appear to be one of kind, but rather of degree. McDermott et al. (2019) note that many positive masculine norms might be thought of as more moderate versions of traditional masculine norms. For example, while believing that "men should put their career above all else" might be deleterious, believing a more modest formulation ("men should strive for success in their career") might be helpful. From our perspective, what is really being invoked by the idea of positive masculinity is a more flexible relationship with masculinity rather than a different type of masculinity per se.

In addition to these conceptual complications, we believe that there are significant sociopolitical reasons for clinicians to tread lightly around concepts like positive or healthy masculinity - particularly for clinicians who want to do clinical work that combats gender inequality. First, encouraging a client to develop a positive masculinity may impose the idea that being masculine is an important value in its own right — or more perniciously, that masculinity needs to be a part of the client's identity in order for them to be healthy. These implicit 
messages, even if unintended, may run counter to attempts at defusing a client from masculinity and additionally can be dismissive of trans, androgynous, and/or non-binary gender identities.

Second, depending on how it is framed, positive masculinity can maintain spurious and harmful assumptions about gender differences. What does it mean, for instance, to say that courage is a positive aspect of masculinity? That courage is unique to men? Or that men are more courageous than people with other gender identities? The science of psychological sex differences is fraught terrain: genuine sex differences are hard to come by (Hyde, 2005). For those differences we do find, it is extremely difficult to disentangle what is innate and what is socially constructed. If we do describe "courage," "dominance," "self-reliance," and so on as essentially masculine qualities, we should be mindful of the fact that we are reifying beliefs that have historically afforded men more powerful social roles.

We urge clinicians to consider these potential hidden messages that may be communicated in discussions of "positive masculinity" and to make a deliberate choice between reconstructing or deconstructing masculinity. For those clinicians who do decide to use positive masculinity as a tool in their work, we think Dewey's case study provides a skillful example of how to do so in a way that avoids essentializing masculinity, invites the client to come as they are in an exploration of gender, and fosters the client's autonomy. In particular, we appreciate Dewey's awareness his own gender and willingness to model a flexible relationship with masculinity. This type of reflexivity is essential in any gender-sensitive psychotherapy with men. Overall, we hope that Dewey's work will inspire clinicians to give masculinity greater attention in their practice and to use his treatment approach as a guide for their own work with men.

\section{REFERENCES}

Addis, M. E., \& Hoffman, E. (2019). The psychology of men in context. New York, NY: Routledge.

Addis, M. E., Mansfield, A. K., \& Syzdek, M. R. (2010). Is "masculinity” a problem?: Framing the effects of gendered social learning in men. Psychology of Men \& Masculinity, 11(2), 77-90. https://doi.org/10.1037/a0018602

Berger, J. L., Addis, M. E., Green, J. D., Mackowiak, C., \& Goldberg, V. (2013). Men's reactions to mental health labels, forms of help-seeking, and sources of help-seeking advice. Psychology of Men \& Masculinity, 14(4), 433-443. https://doi.org/10.1037/a0030175

Beck, A. T., Emery, G., \& Greenberg, R. L. (2005). Anxiety disorders and phobias: A cognitive perspective. New York, NY: Basic Books.

Berke, D. S., Reidy, D., \& Zeichner, A. (2018). Masculinity, emotion regulation, and psychopathology: A critical review and integrated model. Clinical Psychology Review, 66, 106-116. https://doi.org/10.1016/j.cpr.2018.01.004

Dewey, C. (2020). Inflexibly enacted traditional masculinity norms (IE-TMNs) and their impact on adolescent and young adult depression: The hybrid case study of "Tommy." Pragmatic Case Studies in Psychotherapy, 16 (3), Article 1, 237-304. Available: http://pcsp.libraries.rutgers.edu/ 
Gerdes, Z. T., \& Levant, R. F. (2018). Complex relationships among masculine norms and health/well-being outcomes: Correlation patterns of the conformity to masculine norms inventory subscales. American Journal of Men's Health, 12(2), 229-240. https://doi.org/10.1177/1557988317745910

Hayes, S. C., Strosahl, K. D., \& Wilson, K. G. (2012). Acceptance and commitment therapy: The process and practice of mindful change (2nd ed.). New York, NY: Guilford Press.

Hyde, J. S. (2005). The gender similarities hypothesis. American Psychologist, 60(6), 581-592. https://doi.org/10.1037/0003-066X.60.6.581

Kiselica, M. S., Benton-Wright, S., \& Englar-Carlson, M. (2016). Accentuating positive masculinity: A new foundation for the psychology of boys, men, and masculinity. In Y. J. Wong \& S. R. Wester (Eds.), APA handbooks in psychology ${ }^{\circledR}$. APA handbook of men and masculinities (p. 123-143). American Psychological Association. https://doi.org/10.1037/14594-006

Levant, R. F. (2011). Research in the psychology of men and masculinity using the gender role strain paradigm as a framework. American Psychologist, 66(8), 765-776. https://doi.org/10.1037/a0025034

Mahalik, J. R., Locke, B. D., Ludlow, L. H., Diemer, M. A., Scott, R. P. J., Gottfried, M., \& Freitas, G. (2003). Development of the Conformity to Masculine Norms Inventory. Psychology of Men \& Masculinity, 4(1), 3-25. https://doi.org/10.1037/1524-9220.4.1.3

McDermott, R. C., Pietrantonio, K. R., Browning, B. R., McKelvey, D. K., Jones, Z. K., Booth, N. R., \& Sevig, T. D. (2019). In search of positive masculine role norms: Testing the positive psychology positive masculinity paradigm. Psychology of Men \& Masculinities, 20(1), 1222. https://doi.org/10.1037/men0000160

Michniewicz, K. S., Bosson, J. K., Lenes, J. G., \& Chen, J. I. (2016). Gender-atypical mental illness as male gender threat. American Journal of Men's Health, 10(4), 306-317. https://doi.org/10.1177/1557988314567224

Oransky, M., \& Fisher, C. (2009). The development and validation of the meanings of adolescent masculinity scale. Psychology of Men \& Masculinity, 10(1), 57-72. https://doi.org/10.1037/a0013612

Pleck, J. H. (1995). The gender role strain paradigm: An update. In R. F. Levant \& W. S. Pollack (Eds.), A new psychology of men (p. 11-32). New York, NY: Basic Books/Hachette Book Group.

Vandello, J. A., \& Bosson, J. K. (2013). Hard won and easily lost: A review and synthesis of theory and research on precarious manhood. Psychology of Men \& Masculinity, 14(2), 101-113. https://doi.org/10.1037/a0029826

Wong, Y. J., Ho, M.-H. R., Wang, S.-Y., \& Miller, I. S. K. (2017). Meta-analyses of the relationship between conformity to masculine norms and mental health-related outcomes. Journal of Counseling Psychology, 64(1), 80-93. https://doi.org/10.1037/cou0000176

Yousaf, O., Popat, A., \& Hunter, M. S. (2015). An investigation of masculinity attitudes, gender, and attitudes toward psychological help-seeking. Psychology of Men \& Masculinity, 16(2), 234-237. https://doi.org/10.1037/a0036241 